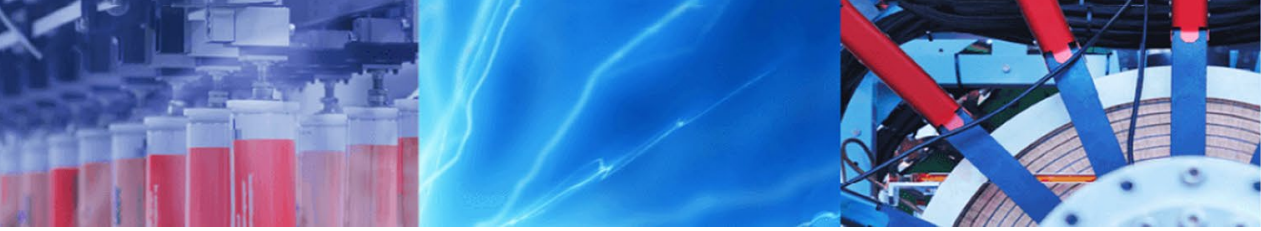

Research Article

\title{
Development and validation of residual solvent determination by headspace gas chromatography in Imatinib Mesylate API
}

\author{
Chandrakant Sojitra $^{1,2,3} \cdot$ Ajay Tehare $^{1} \cdot$ Chintan Dholakia $^{1} \cdot$ Padmaja Sudhakar $^{2} \cdot$ Sameer Agarwal $^{3}$ D . \\ Kumar K. Singh ${ }^{1}$
}

(c) Springer Nature Switzerland AG 2019

\begin{abstract}
An accurate, precise, robust and sensitive method was developed for residual solvents determination by fast static headspace gas chromatography (HSGC) with flame ionization detector in Imatinib Mesylate API. Residual solvents in drug substances are quantified using gas chromatography with headspace. As per regulatory guidelines, residual solvents must be controlled for release any batches of active pharmaceutical ingredients (API). This paper includes the development and validation of HSGC method for the determination of residual solvents specifically methanol, acetone, dichloromethane, n-hexane, ethyl acetate and pyridine in Imatinib Mesylate API. Imatinib Mesylate is a specific inhibitor of BCR-ABL tyrosine kinase. DB-624 capillary column, $30 \mathrm{~m}$ long $\times 0.53 \mathrm{~mm}$ internal diameter, the $3 \mu \mathrm{m}$ film thickness was used for analysis. To minimize degradation, injector temperature was set at $170^{\circ} \mathrm{C}$. The initial oven temperature was kept at $35^{\circ} \mathrm{C}$ for 2 min and used ramp 1 at a rate of $4{ }^{\circ} \mathrm{C} \mathrm{min}-1$ to temperature of $80^{\circ} \mathrm{C}$ hold for 0 min and used ramp 2 at a rate of $40^{\circ} \mathrm{C} \mathrm{min}{ }^{-1}$ to a final temperature of $230^{\circ} \mathrm{C}$ for $12 \mathrm{~min}$ hold time. Nitrogen was selected as a carrier gas. 1-Methyl-2-Pyrrolidinone (NMP) was used as a sample solvent. The method can be readily used to determine defined residual solvents present in a various range of APIs, intermediates, excipients and drug products.
\end{abstract}

Keywords Residual solvents · Imatinib Mesylate · Headspace gas chromatography · Flame ionization detector · Method validation

\section{Introduction}

Residual solvents or volatile organic solvents are used or formed during the manufacturing of pharmaceutical drug substances, intermediates, excipients or pharmaceutical drug product [1]. The solvents are toxic, have no therapeutic importance and affect the quality and stability of drug substances and drug products so they are not desirable in the final product [2-4]. Although it is difficult to remove completely with the common techniques used in practical manufacturing process such as increased process temperature or/and decreased pressure, they need to be minimized. However, depending on the nature of the API, residual solvents and drying condition of the process, some amount of residual solvents traces can be retained in the final drug substances or drug product. Thus, acceptable levels of many residual solvents are included in regulatory guideline; particularly in guideline Q3C issued by the International Conference on Harmonization of technical requirements for registration of pharmaceuticals for

Electronic supplementary material The online version of this article (https://doi.org/10.1007/s42452-019-0233-x) contains supplementary material, which is available to authorized users.

Chandrakant Sojitra, chandrakant.sojitra@yahoo.com; $₫$ Sameer Agarwal, sameeragarwal@zyduscadila.com | ${ }^{1}$ API Division, Cadila Healthcare Limited, Sarkhej-Bavla N.H. No. 8 A, Changodar, Ahmadabad 382210, India. ${ }^{2}$ Department of Chemistry, Faculty of Science, M.S.University of Baroda, Baroda 390002, India. ${ }^{3}$ Zydus Research Centre, Cadila Healthcare Ltd., Sarkhej-Bavla N.H. No. 8 A, Moraiya, Ahmadabad 382210, India. 
human use (ICH) $[5,6]$. ICH has also included daily exposure limit of many solvents it has classified these solvents into four classes on the basis of the toxicity level and the degree to which they can be considered an environmental hazard [6]. Class I solvents (which covers 5 residual solvents) are known or suspected human carcinogens and environmental hazards, the use of these solvents should be avoided. Class I solvents should be identified and quantified. Class II solvents (which covers 29 residual solvents) are non-genotoxic animal carcinogens or possible causative agents of other irreversible toxicity such as neurotoxicity or teratogenicity. Use of these solvents should be limited. Class II solvents have individual limits. Class III solvents (which covers 26 residual solvents) having low toxic potential to man; no health-based exposure limit is needed. Class 3 solvents have PDEs of $50 \mathrm{mg}$ or more per day. Finally, Class 4 solvents are those for which no adequate toxicological data have been found [7]. Therefore determination of residual solvents becomes a necessary procedure for quality control of drug substances and drug product to meet regulatory guideline and ensure patient safety $[8,9]$.

Head space gas chromatography (HSGC) is generally used to determine residual solvents because of its high separation efficiency and sensitivity for organic volatile solvents [10]. However head space bounds the analysis to those solvents being evaporated from HS only, it also requires larger sample load and analysis time should be longer due to sample equilibration. Headspace sampling is preferred because of its ability to avoid direct liquid or solid injection [11, 12]. HSGC methods minimize any possible interference caused by non-volatile substances or by the degradation/decomposition products of the non-volatile components. While comparing to headspace, direct injection method requires relatively low sample concentration, but the high boiling/ melting point components of the sample may not be eluted through GC Column and they may contaminate the GC injection port and leads to poor chromatography. HSGC with FID detection has been mainly used for the analysis of organic volatile solvents present in the pharmaceutical drug substances and drug products [13-16].
Battu et al. have developed the residual solvent method where ethyl acetate and hexane has not been separated [17], while Adepu et al. have reported a method in which acetone and DCM has not been separated [18]. In addition, Puranik et al. have described the study on few residual solvents [19]. However, this method has some drawbacks, for example: dimethyl sulfoxide was used as diluent, which decomposes thermally to produce dimethyl sulfide; resolution between solvents is less than 1.5 and has been injected at low concentration; standard of residual solvents were not prepared as per ICH limit, etc.

This report describes the separation of six residual solvents, among which two pair of solvents were critical i.e. $\mathrm{n}$-hexane and ethyl acetate, and DCM and acetone using headspace gas chromatography (HSGC) with flame ionization detector (FID) in Imatinib Mesylate API. Moreover, method was developed considering sample matrix and accuracy, precision and linearity were established.

Imatinib Mesylate is a tyrosine kinase inhibitor, used to treat patients with hematological malignancies or malignant sarcomas such as gastrointestinal stromal tumors, chronic myeloid leukemia, acute lymphoblastic leukemia, gastrointestinal stromal tumors [20, 21]. Imatinib Mesylate is designated chemically as 4-[(4-methylpiperazine-1-yl)methyl]-N-(4-methyl-3-\{[4(pyridin-3-yl)pyrimidin-2-yl]amino\} phenyl) benzamide methanesulfonate (Fig. 1), is a specific inhibitor of the tyrosine kinase in $\mathrm{BCR}-\mathrm{ABL}^{+}$cell [22]. It is an approved drug for treatment of gastrointestinal stromal tumor since 2002 [21] and for chronic myelogenous leukemia since 2011 [23] from the United States food and drug administration. Six solvents are required for the synthesis of Imatinib Mesylate i.e. methanol, acetone, dichloromethane, n-hexane, ethyl acetate and pyridine [24] and these should be controlled in final API.

In this research article, we have been described a development and validation of an HS-GC analytical method for determination of six residual solvents used in the route of synthesis to produce the Imatinib Mesylate drug substances. Incorporated Residual solvents Permissible daily exposure limit and $\mathrm{ICH}$ class categories are described in Table 1.<smiles>Cc1ccc(NC(=O)c2ccc(CN3CCN(C)CC3)cc2)cc1Nc1nccc(-c2cccnc2)n1</smiles>

Fig. 1 Chemical structure of Imatinib Mesylate 
Table 1 Class of the residual solvents of Imatinib Mesylate as per the ICH guidelines

\begin{tabular}{llllcc}
\hline S. no & $\begin{array}{l}\text { Name of residual } \\
\text { solvent in Imatinib } \\
\text { Mesylate }\end{array}$ & $\begin{array}{l}\text { Class of } \\
\text { solvent }\end{array}$ & $\begin{array}{l}\text { Permissible daily } \\
\text { exposure (PDE) }(\mathrm{mg} / \\
\text { day) }\end{array}$ & ICH Limit (ppm) & Density $\left(\mathrm{kg} / \mathrm{m}_{3}\right)$ \\
\hline 1 & Methanol & II & 30.0 & 3000 & 791.80 \\
2 & Acetone & III & 50.0 & 5000 & 791.00 \\
3 & Dichloromethane & II & 6.0 & 600 & 1326.00 \\
4 & n-Hexane & II & 2.9 & 290 & 659.1 \\
5 & Ethyl acetate & III & 50 & 5000 & 897.00 \\
6 & Pyridine & II & 2.0 & 200 & 981.90 \\
\hline
\end{tabular}

\section{Experimental}

\subsection{Chemical, material, and reagents}

Imatinib Mesylate API was synthesized in Cadila Healthcare Ltd. (Ahmedabad, Gujarat, India) [25]. Methanol, acetone, dichloromethane (DCM), n-hexane, ethyl acetate and pyridine were purchased from Merck (India). 1-Methyl2-Pyrrolidinone (NMP) was purchased from Spectrochem (Mumbai, India).

\subsection{Instrumentation}

HSGC system of an Agilent technologies 6890N equipped with a flame ionization detector with a headspace sampler (Agilent technologies G1888) was used for method development and method validation studies. A $2 \mathrm{~mm}$ I.D. deactivated direct split liner was used as an inlet liner and chemstation software was used for data acquisition and chromatographic data integration. A Sartorius micro balance CP225D (Germany) and micro-pipette (100-1000 $\mu \mathrm{L}$ from Borosil) were used.

\subsection{Gas chromatographic conditions}

$30 \mathrm{~m} \times 0.53 \mathrm{~mm}$ I.D., $3.0 \mu \mathrm{m}$ film thickness DB-624 (bonded 6\% cyanopropylphenyl-94\% dimethylpolysiloxane) capillary GC column to achieve proper Separation in a developed method. DB-624 column was manufactured by J\&W Scientific (Agilent Scientific Technologies, Wilmington, DE, USA). The GC method parameters, headspace sampler conditions, and oven temperature programming of the method have been mentioned in Table 2 .

\subsection{Preparation of standard and sample solution}

Standard solution of residual solvent was prepared according to respective $\mathrm{ICH}$ limit. A composite standard stock solution of all the known residual solvent was prepared in such a way that it contains a final concentration of 300 ppm for methanol, 500 ppm for acetone, 60 ppm for dichloromethane, 29 ppm of n-hexane, 500 ppm for ethyl acetate and 20 ppm for pyridine in NMP.

The blank vial was prepared with $1.0 \mathrm{~mL}$ of NMP, the standard vial was prepared with $1.0 \mathrm{~mL}$ of the standard solution and the sample vials were prepared with $100 \mathrm{mg}$ per $1.0 \mathrm{~mL}$ NMP.

\subsection{Method validation}

The method validation was performed by evaluating specificity, limit of detection (LOD), limit of quantitation (LOQ), linearity, accuracy, intermediate precision, system suitability and method precision of residual solvents as specified in the ICH harmonized tripartite guideline (2005).

\section{Result and discussion}

\subsection{Gas chromatographic analytical method development}

Method development by HSGC involves critical parameter such as selection of sample solvent, detector, column, carrier gas, optimization of headspace condition and chromatographic conditions. Developed method should be specific, sensitive, robust and QC friendly. The critical parameter of the developed method is discussed below.

\subsubsection{Selection of detector and carrier gas}

A flame ionization detector (FID) was used for this method because FID has good sensitivity. The carrier gas was selected as nitrogen because it is economical as compared to helium.

\subsubsection{Selection of column}

The GC Column is a crucial parameter for developing an efficient and sensitive HSGC method. The residual solvents were commonly determined by bonded 6\% cyanopropylphenyl-94\%dimethylpolysiloxane (624) column due to 
Table 2 Experimental condition for determination of residual solvents of Imatinib Mesylate API

\begin{tabular}{|c|c|c|c|c|}
\hline Components & Parameters & \multicolumn{3}{|l|}{ Requirements } \\
\hline \multirow[t]{9}{*}{ Headspace condition } & Injection volume & $1 \mathrm{ml}$ & & \\
\hline & G.C cycle time & $40 \mathrm{~min}$ & & \\
\hline & Oven temperature & $80^{\circ} \mathrm{C}$ & & \\
\hline & Loop temperature & $90^{\circ} \mathrm{C}$ & & \\
\hline & Transfer line temperature & $110^{\circ} \mathrm{C}$ & & \\
\hline & Sample equilibration time & $30 \mathrm{~min}$ & & \\
\hline & Loop equilibration time & $0.20 \mathrm{~min}$ & & \\
\hline & Loop fill time & $0.10 \mathrm{~min}$ & & \\
\hline & Inject time & $1 \min$ & & \\
\hline \multirow[t]{5}{*}{ Injector } & Carrier gas & Nitrogen & & \\
\hline & Injector temperature & $200^{\circ} \mathrm{C}$ & & \\
\hline & Gas flow (constant pressure) & $2.3 \mathrm{psi}$ & & \\
\hline & Injection mode & Split 1:2 & & \\
\hline & Liner & Glass liner & & \\
\hline \multirow[t]{5}{*}{ Column } & \multicolumn{4}{|c|}{ DB-624 (30 m long $\times 0.53 \mathrm{~mm}$ I.D $\times 3 \mu \mathrm{m}$ film thickness) $6 \%$ cyanopropylphenyl and 94\% dimethylpolysiloxane } \\
\hline & Oven temperature program & Increment rate $\left({ }^{\circ} \mathrm{C} / \mathrm{min}\right)$ & Temperature $\left({ }^{\circ} \mathrm{C}\right)$ & Hold time (min) \\
\hline & & - & 35 & 2 \\
\hline & & 4 & 80 & 0 \\
\hline & & 40 & 230 & 12 \\
\hline \multirow[t]{6}{*}{ Detector } & Total program time & $29.0 \mathrm{~min}$ & & \\
\hline & Type & FID & & \\
\hline & Temperature & $260^{\circ} \mathrm{C}$ & & \\
\hline & Hydrogen flow & $40 \mathrm{ml} / \mathrm{min}$ & & \\
\hline & Airflow & $400 \mathrm{ml} / \mathrm{min}$ & & \\
\hline & Make up flow (N2) & $25 \mathrm{ml} / \mathrm{min}$ & & \\
\hline
\end{tabular}

its mid-polar nature, higher temperature limit than other polar columns (DB-Wax), and higher retention of polar solvents compare to non-polar column (DB-1). The retention of polar solvents on a DB-624 column is relatively stronger at high temperatures and could provide high separation between solvents which has minor differences in boiling points. Since the objective was to develop an efficient HSGC method, a DB-624 column $(30 \mathrm{~m} \times 0.53 \mathrm{~mm}, 3.0 \mu \mathrm{m}$ film thickness) was selected, which is commonly used for residual solvent determination [26-29]. As shown in Fig. 2 of the representative chromatograms for the method using DB-624 column, all residual solvents present in Imatinib Mesylate API were well separated from each other and from diluent also. To separate dichloromethane and acetone was highly critical by HSGC. Resolutions of this critical pairs were 6.3 in a developed method. To define the effect of the stationary phase on the resolution, a non-polar GC column DB-1 (100\% dimethyl polysiloxane) used with the same chromatographic conditions of the developed method. Resolution of a critical pair was decreased to 1.2 from 6.3 with DB-1 Column. These results clearly indicated that the DB-624 column is the best choice for the separation of all six residual solvents in Imatinib Mesylate API.

\subsubsection{Selection of sample solvent}

Several solvents were tried mainly DMF, DMSO and NMP for sample solvents and it was observed that NMP gave smooth baseline with no interference at the retention times of the targeted solvents. DMS Peak was formed during heating in an oven when using DMSO as sample solvents. DMF gave baseline interference at the retention time of Pyridine. So finally NMP was used as the standard and sample solvent because of its ability to dissolve a wide variety of drug substances. It has a high boiling point $\left(202{ }^{\circ} \mathrm{C}\right)$ that does not interfere with the analysis of volatile solvents.

\subsubsection{Chromatographic conditions}

To develop an HSGC method, there are two strategies for selecting oven programs. The first strategy was to keep 
FID1 A, (D:I2018VITB-B-FORMIDATAWANI060117_04_ITB_B_RS 2018-01-06 17-40-57ISIG20000008.D)

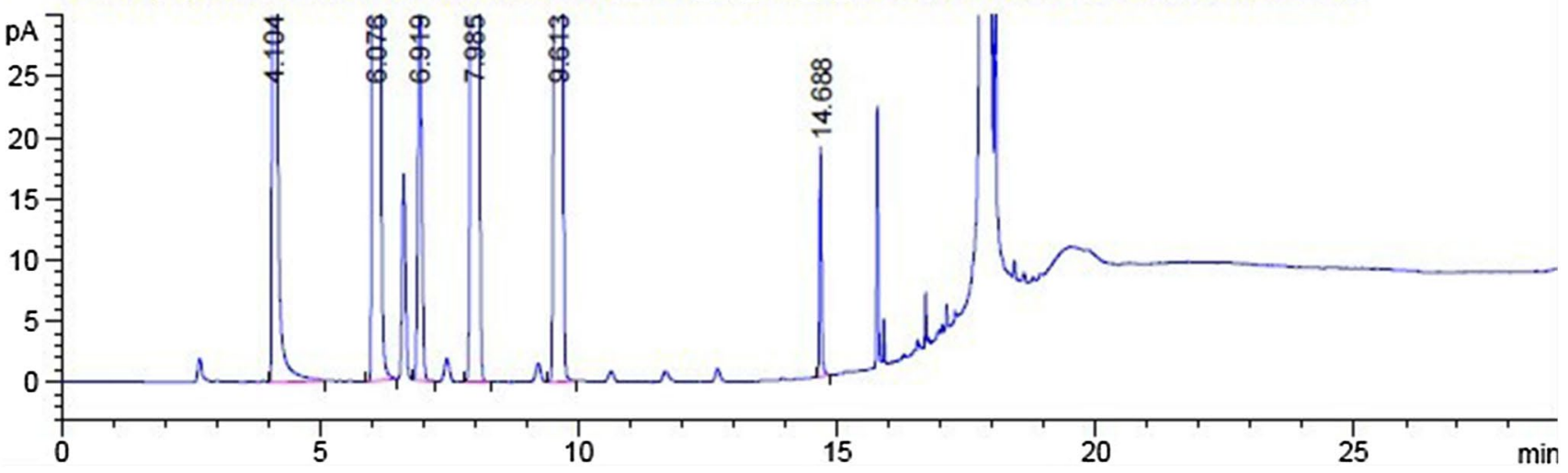

Fig. 2 Typical chromatogram of the six composite standard solution

initial oven temperature low and then gradient elution and in second strategy isothermal elution at relatively high oven temperatures. We wanted to increase the retention time of methanol, so we choose the first strategy to start our method development and finalized $35^{\circ} \mathrm{C}$ Temp as initial oven temp with Hold time for 2 min. After that in ramp 1 , a slow gradient was applied i.e. $4^{\circ} \mathrm{C} / \mathrm{min}$ to $80^{\circ} \mathrm{C}$ to resolve the critical pairs, dichloromethane and acetone. To elute other high boiling unknown impurities and NMP, which is having $202^{\circ} \mathrm{C}$ boiling point, oven temp set at $40{ }^{\circ} \mathrm{C} / \mathrm{min}$ increment to $230^{\circ} \mathrm{C}$ with $12 \mathrm{~min}$ Final hold time. The flow rate of nitrogen was finalized at $3.3 \mathrm{~mL} / \mathrm{min}$ which is equivalent to $24 \mathrm{~cm} / \mathrm{s}$ of linear velocity. Finally, the method was developed with a total run time of about $29 \mathrm{~min}$.

\subsubsection{Optimization of headspace parameters}

The sensitivity of the HSGC method was directly impacted by headspace oven temperature, Headspace oven Temperature should be kept same or above the boiling point of the residual solvents but below the boiling point of the sample solvents. To minimize the carryover problems Loop temperature has been kept $10-15^{\circ} \mathrm{C}$ higher than oven temperature and the transfer line temperature also has been kept $10-15^{\circ} \mathrm{C}$ higher than the loop temperature [30]. Headspace oven temperature was kept at $80^{\circ} \mathrm{C}$ because among all residual solvents pyridine has a highest boiling point of $80^{\circ} \mathrm{C}$. The boiling point of the NMP is $202{ }^{\circ} \mathrm{C}$. Therefore, the headspace oven, loop, and transfer line temperatures were selected at $80^{\circ} \mathrm{C}, 90^{\circ} \mathrm{C}$ and $110^{\circ} \mathrm{C}$, respectively. The vial equilibration time was set to $30 \mathrm{~min}$. Other headspace parameter has been described in Table 2.

\subsection{Method validation}

The final method was validated per requirements prescribed in ICH guidelines [31].

\subsubsection{Specificity}

The method specificity was demonstrated by injecting the Blank, individual residual solvents standard solution (chromatogram has been attached in Fig. S-2) and specificity solution (composite standard solution of all residual solvents). In the developed chromatographic method, no interference was observed at the retention time of targeted residual solvents from each other and from sample solvents or other unknown peaks. The retention time of methanol, acetone, dichloromethane (DCM), n-hexane, ethyl acetate and pyridine was found to be $4.10,6.07$, $6.92,7.99,9.61$ and $14.69 \mathrm{~min}$, respectively. The retention time of sample solvent (NMP) was found to be $18.0 \mathrm{~min}$. A typical chromatogram of the standard solution is shown in Fig. 2.

\subsubsection{Linearity and range}

The linearity of the method was determined using 7 concentration level over the range $20-150 \%$ of ICH Limit Level. The calibration curve was found to be linear within the range and correlation coefficient $\left(r^{2}\right)$ values for all six residual solvents were found to be higher than 0.99 . Linearity curve and values for the residual solvents have been provided in Fig. 3 and Table 3. Each residual solvent was easily passed acceptance criteria for accuracy, system precision, method precision and linearity from the low concentration to high concentration, therefore the range of the method was 60-450 ppm for methanol, 100-750 ppm for acetone, 15-100 ppm for dichloromethane, 6-50 ppm 

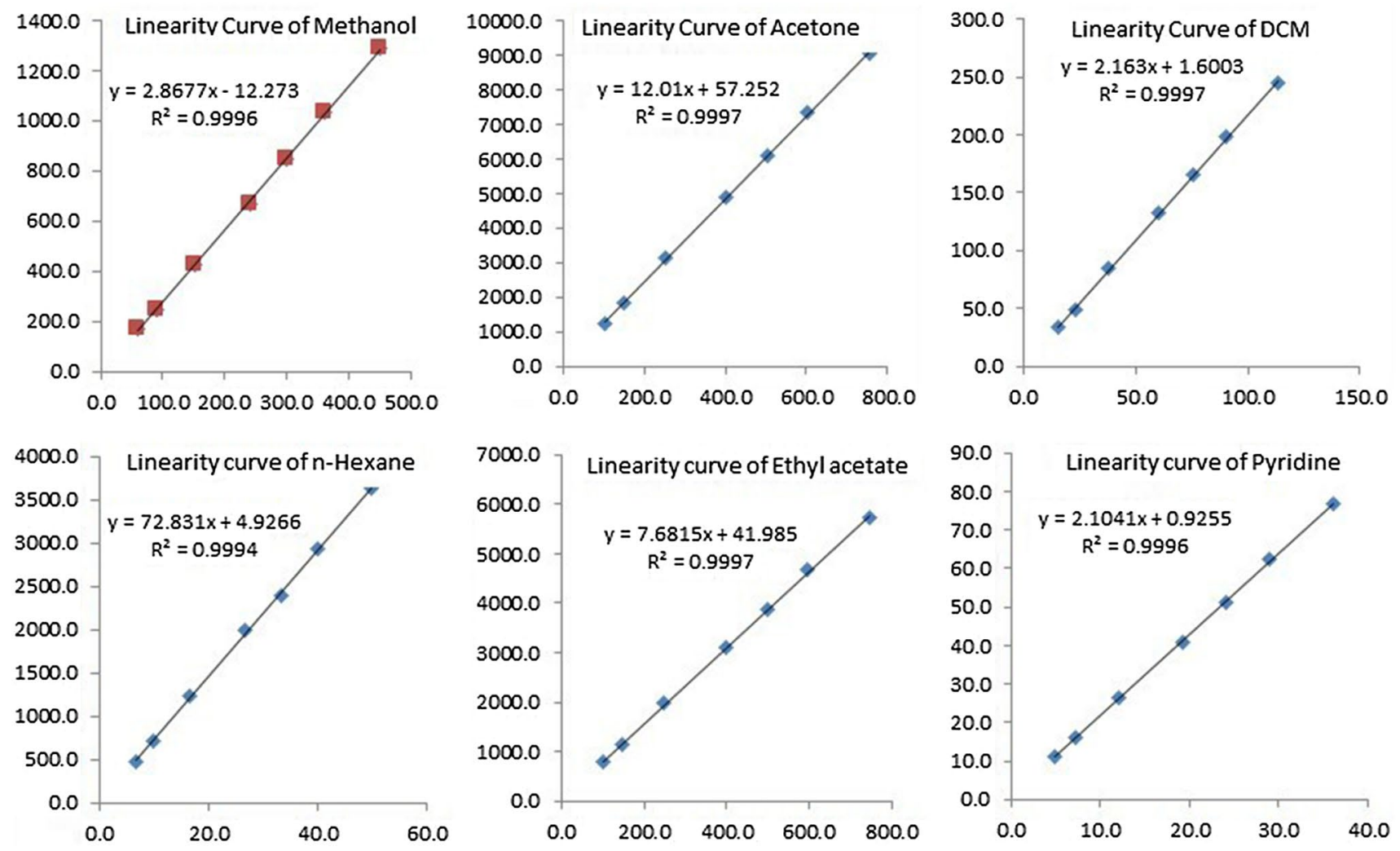

$X$-axis- Concentration in ppm Y-axis- Peak area in pA

Fig. 3 Linearity plot of residual solvents

Table 3 Linearity sample concentration and results

\begin{tabular}{|c|c|c|c|c|c|c|c|c|c|}
\hline \multirow[t]{2}{*}{ Solvent name } & \multicolumn{7}{|c|}{ Conc. range $(\mu \mathrm{g} / \mathrm{ml})$} & \multirow[t]{2}{*}{ Regression equation $(\mathrm{Y}=\mathrm{ax}+\mathrm{b})$} & \multirow{2}{*}{$\begin{array}{l}\text { Correlation } \\
\text { coefficient }\end{array}$} \\
\hline & LOQ & $30 \%$ & $50 \%$ & $80 \%$ & $100 \%$ & $120 \%$ & $150 \%$ & & \\
\hline Methanol & 60.3 & 90.4 & 150.7 & 241.2 & 301.5 & 361.8 & 452.2 & $Y=2.8677 x-12.273$ & 0.9996 \\
\hline Acetone & 100.6 & 150.9 & 251.4 & 102.3 & 502.9 & 303.5 & 754.3 & $Y=12.01 x+57.252$ & 0.9997 \\
\hline Dichloromethane & 15.1 & 22.6 & 37.7 & 60.3 & 75.4 & 90.5 & 113.1 & $Y=2.613 x+1.6003$ & 0.9997 \\
\hline n-Hexane & 6.7 & 10.0 & 16.6 & 26.6 & 33.3 & 39.9 & 49.9 & $Y=72.831 x+4.9268$ & 0.9994 \\
\hline Ethyl acetate & 99.6 & 149.4 & 249.1 & 398.5 & 498.1 & 597.7 & 747.2 & $Y=7.6815 x+41.985$ & 0.9997 \\
\hline Pyridine & 4.8 & 7.2 & 12.0 & 19.3 & 24.1 & 28.9 & 36.1 & $Y=2.1041 x+0.9255$ & 0.9996 \\
\hline
\end{tabular}

for n-hexane, 100-750 ppm for ethyl acetate and 5-35 ppm for pyridine.

\subsubsection{Method sensitivity}

The LOQ were determined based on a signal-to-noise ratio of 3:1 and 10:1 respectively. Based on validation results, LOQ limit was found to be 60.3 ppm for methanol, 100.6 ppm for acetone, 15.1 ppm for dichloromethane, 6.7 ppm for $n$-hexane, 99.6 ppm for ethyl acetate and 4.8 ppm for pyridine. Accuracy at LOQ level was confirmed by injecting three different preparations of Imatinib spiked with each residual solvents at LOQ level and calculated \% recoveries of each solvent.

\subsubsection{Accuracy (recovery)}

The accuracy of the method was determined by spiking of all solvents at four different level i.e. LOQ Level, $50 \%$ level, $100 \%$ level, and $150 \%$ level of ICH limit in a triplicate analysis. Recovery for all six solvents was found within the range of $80-120 \%$. Recovery study and 
Table 4 Accuracy and method precision data

\begin{tabular}{|c|c|c|c|c|c|c|}
\hline Accuracy level & Methanol & Acetone & $\begin{array}{l}\text { Dichlo- } \\
\text { romethane }\end{array}$ & n-Hexane & Ethyl acetate & Pyridine \\
\hline \multicolumn{7}{|l|}{ LOQ recovery } \\
\hline LOQ R-1 & 99.0 & 103.6 & 104.4 & 106.3 & 105.8 & 98.8 \\
\hline LOQ R-2 & 99.4 & 102.9 & 104.9 & 106.1 & 106.2 & 95.7 \\
\hline LOQ R-3 & 96.4 & 104.2 & 105.9 & 106.9 & 107.2 & 93.0 \\
\hline \multicolumn{7}{|l|}{$50 \%$ level recovery } \\
\hline $50 \%$ level R-1 & 100.3 & 106.2 & 106.4 & 109.6 & 108.4 & 98.7 \\
\hline $50 \%$ level R-2 & 97.9 & 105.0 & 105.8 & 108.4 & 107.5 & 100.9 \\
\hline $50 \%$ level R-3 & 100.3 & 105.8 & 106.8 & 109.9 & 108.5 & 102.8 \\
\hline \multicolumn{7}{|c|}{$100 \%$ level recovery (method precision) } \\
\hline Spike solution-1 & 97.4 & 93.1 & 103.7 & 108.2 & 105.2 & 98.0 \\
\hline Spike solution-2 & 98.9 & 93.3 & 103.5 & 107.7 & 104.9 & 100.0 \\
\hline Spike solution-3 & 99.5 & 93.8 & 104.2 & 108.9 & 105.5 & 101.4 \\
\hline Spike solution-4 & 97.5 & 93.2 & 103.6 & 108.6 & 105.1 & 99.9 \\
\hline Spike solution-5 & 99.1 & 93.8 & 104.0 & 109.5 & 105.6 & 100.8 \\
\hline Spike solution-6 & 100.1 & 94.2 & 104.5 & 109.6 & 106.0 & 101.3 \\
\hline \multicolumn{7}{|c|}{$150 \%$ level recovery } \\
\hline $150 \%$ level R-1 & 99.0 & 101.7 & 102.5 & 106.7 & 103.9 & 99.3 \\
\hline $150 \%$ level R-2 & 99.2 & 102.1 & 102.7 & 108.2 & 104.2 & 96.9 \\
\hline $150 \%$ level R-3 & 97.7 & 100.6 & 101.3 & 107.0 & 102.9 & 93.9 \\
\hline \%RSD overall & 1.3 & 1.9 & 1.8 & 1.3 & 1.9 & 3.3 \\
\hline
\end{tabular}

method precision results were reported in Table 4 and indicate that the method was accurate.

\subsubsection{Precision}

The precision of the method was determined by system precision (six replicate injection of standard solution) and method precision (six different preparation of spike solution) studies. In both the studies \%Relative Standard Deviation of peak areas for all the solvents were less than $5.0 \%$. The results were provided in Table 5. These results proved that the system suitability was passed and method is precise (Table 5).

\subsubsection{System suitability}

The system suitability criterion was taken to be the resolution between the closely eluting pairs, i.e. acetone and dichloromethane. The system suitability was checked by injecting the standard solution before starting any analysis of residual solvents. The criterion for system suitability was that the resolution between the closely eluting pair should not be less than 1.5 and it was found that optimum resolution 6.3 was achieved (Table 5). Other system suitability parameter chromatogram has been attached in Fig. S-1.

\subsubsection{Robustness}

Robustness of the method was performed by slightly changing carrier gas flow rate, oven temperature and split ratio. The following parameters were changed: column
Table 5 System precision and system suitability parameter

\begin{tabular}{lcllll}
\hline Solvent name & RT (min) & USP resolution & USP tailing factor & $\begin{array}{l}\text { USP theo- } \\
\text { retical plate }\end{array}$ & $\begin{array}{l}\text { \%RSD }(\mathrm{n}=6) \\
\text { of peak area }\end{array}$ \\
\hline Methanol & 4.10 & - & 1.292 & 20,863 & 4.6 \\
Acetone & 6.07 & 16.0 & 1.028 & 33,847 & 1.9 \\
Dichloromethane & 6.92 & 6.3 & 1.065 & 42,971 & 2.5 \\
n-Hexane & 7.98 & 7.3 & 1.003 & 39,627 & 2.1 \\
Ethyl acetate & 9.61 & 10.4 & 0.996 & 62,912 & 2.3 \\
Pyridine & 14.69 & 45.0 & 1.162 & 652,171 & 4.3 \\
\hline
\end{tabular}


Table 6 Results of robustness study

\begin{tabular}{|c|c|c|c|c|c|c|}
\hline \multirow[t]{2}{*}{ Parameter/variation } & \multicolumn{6}{|c|}{ USP resolution } \\
\hline & Methanol & Acetone & DCM & n-Hexane & Ethyl acetate & Pyridine \\
\hline As such conditions & NA & 16.0 & 6.3 & 7.3 & 10.4 & 45.0 \\
\hline \multicolumn{7}{|l|}{ Flow rate (psi) } \\
\hline a. 2.0 & NA & 16.4 & 6.4 & 7.4 & 10.6 & 48.0 \\
\hline b. 2.5 & NA & 15.2 & 6.1 & 6.9 & 96 & 38.2 \\
\hline \multicolumn{7}{|c|}{ Column oven Temp. $\left({ }^{\circ} \mathrm{C}\right)$} \\
\hline a. 32 & NA & 16.5 & 6.5 & 7.5 & 10.5 & 45.8 \\
\hline b. 38 & NA & 12.6 & 5.9 & 6.8 & 10.1 & 44.2 \\
\hline \multicolumn{7}{|l|}{ Split ratio } \\
\hline a. $1: 1.8$ & NA & 16.4 & 6.6 & 7.8 & 10.6 & 45.6 \\
\hline b. $1: 2.2$ & NA & 16.1 & 6.1 & 7.1 & 10.1 & 44.3 \\
\hline
\end{tabular}

Table 7 Residual solvents contents in the commercial batch of Imatinib Mesylate API

\begin{tabular}{llll}
\hline Solvent name & Batch set-1 & Batch set-2 & Batch set-3 \\
\hline Methanol & $988 \mathrm{ppm}$ & $954 \mathrm{ppm}$ & $928 \mathrm{ppm}$ \\
Acetone & $513 \mathrm{ppm}$ & $535 \mathrm{ppm}$ & $522 \mathrm{ppm}$ \\
Dichloromethane & $\mathrm{ND}$ & $\mathrm{ND}$ & $\mathrm{ND}$ \\
n-Hexane & $0.5 \mathrm{ppm}$ & $0.4 \mathrm{ppm}$ & $0.5 \mathrm{ppm}$ \\
Ethyl acetate & $4.1 \mathrm{ppm}$ & $4.2 \mathrm{ppm}$ & $4.5 \mathrm{ppm}$ \\
Pyridine & $\mathrm{ND}$ & $\mathrm{ND}$ & $\mathrm{ND}$ \\
\hline
\end{tabular}

oven temperature $\pm 3{ }^{\circ} \mathrm{C}$ from the ideal conditions (initial column oven temperature at $32^{\circ} \mathrm{C}$ and $38^{\circ} \mathrm{C}$ ), the flow rate $\pm 5 \%$ from the ideal conditions (flow rate 2.0 psi and $2.5 \mathrm{psi}$ ), the split ratio $\pm 10 \%$ from the ideal conditions (the split ratio of $1: 1.8$ and $1: 2.2$. The results have been mentioned in Table 6. No significant difference in \% RSD, resolution and elution order which indicate that the method is robust. Results of robustness study were reported in Table 6.

\section{Result}

Residual solvents analysis was performed on developed and validated method for commercial batch of Imatinib Mesylate API in triplicate. Results were reported in Table 7 and chromatogram has been attached in Fig. S-3.

\section{Conclusion}

A selective and sensitive fast static HSGC method has been successfully developed for the determination of methanol, acetone, dichloromethane, n-hexane, ethyl acetate and pyridine in Imatinib Mesylate API through consideration of route of synthesis and solvents nature. The developed method was successfully validated as per regulatory guideline and found to be precise, accurate, linear, robust and specific. Additionally, our method is suitable for analysis of pyridine and other solvents in one single method, which is accurate, precise and linear in presence of sample matrix. However only a limited number of solvents are used in Imatinib Mesylate API, this method may be used to separate the residual solvents present in other drug substances and can be used for routine analysis to monitor in-process drying and in quality control for bulk drug manufacturing. Taken together, our developed HSGC method demonstrated precise, economical and commercially viable quantitative technique for residual solvents determination in Imatinib Mesylate API which will also be advantageous for industrial scale manufacturing.

Acknowledgements The authors would like to acknowledge the management of Cadila Healthcare Ltd. for support and encouragement. ZRC Communication No. 575.

\section{Compliance with ethical standards}

Conflict of interest The authors declare that they have no conflict of interest.

\section{References}

1. Sitaramaraju Y, Van Hul A, Wolfs K, Schepdael AV, Hoogmartens J, Adams E (2008) Static headspace gas chromatography of semi-volatile drugs in pharmaceuticals for topical use. J Pharm Biomed Anal 47:834-840

2. Antolín EM, Quinonez YB, Canavaciolo VG, Cruz ER (2008) Validation of an analytical method for quality control of residual solvents ( $\mathrm{n}$-hexane and acetone) in D-002: new active ingredient from beeswax. J Pharm Biomed Anal 47:646-650

3. Nojavan S, Ghassempour A, Bashour Y, Darbandi MK, Ahmadi $\mathrm{SH}$ (2005) Determination of residual solvents and investigation of their effect on ampicillin trihydrate crystal structure. J Pharm Biomed Anal 36:983 
4. Witschi C, Doelker E (1997) Residual solvents in pharmaceutical products: acceptable limits, influences on physicochemical properties, analytical methods and documented values. Eur J Pharm Biopharm 43:215-242

5. Proceedings of international conference on harmonization of technical requirements for registration of pharmaceuticals for human use (ICH-2016), tripartite harmonized guideline (Q3C) impurities: residual solvents

6. Gomes PCFL, D'Andrea ED, Mendes CB, Siqueira MEPB (2010) Determination of benzene, toluene and $\mathrm{N}$-hexane in urine and blood by headspace solid-phase microextraction/gas-chromatography for the biomonitoring of occupational exposure. J Braz Chem Soc 21:119

7. Harmonized Tripartite Guideline on Maintenance of Note for Guidance on Impurities: Residual Solvents (Q3C (M)) (2016) International conference on harmonization of technical requirements for registrations of pharmaceuticals for human use $(\mathrm{ICH})$, Geneva

8. Residual solvents $\langle 467\rangle$, the United States Pharmacopoeia, USP38/NF33 (2012) the United States Pharmacopeial Convention, Rockville, MD, USA

9. Identification and control of residual solvents (2.4.24). In: European Pharmacopoeia (2013), 8th edn. European Directorate for the Quality of Medicines \& HealthCare, Strasbourg, France

10. Kolb B, Ettre LS (1991) Theory and practice of multiple headspace extraction. Chromatographia 32:505-513

11. Zhu JY, Chai XS (2005) Some recent developments in headspace gas chromatography. Curr Anal Chem 1:79-83

12. B'Hymer C (2003) Residual solvent testing: a review of gas-chromatographic and alternative techniques. Pharm Res 20:337-344

13. Camarasu CC, Mezei-Szuts M, Varga GB (1998) Residual solvents determination in pharmaceutical products by GC-HD and GCMS-SPME. J Pharm Biomed Anal 18:623-638

14. Laus G, Andre M, Bentivoglio G, Schottenberger H (2009) lonic liquids as superior solvents for headspace gas chromatography of residual solvents with very low vapor pressure, relevant for pharmaceutical final dosage forms. J Chromatogr A 1216:6020-6023

15. Yarramraju S, Akurathai V, Wolfs K, Van Schepdael A, Hoogmartens J, Adams E (2007) Investigation of sorbic acid volatile degradation products in pharmaceutical formulations using static headspace gas chromatography. J Pharm Biomed Anal 44:456-463

16. Otero R, Carrera G, Dulsat JF, Fabregas JL, Claramunt J (2004) Static headspace gas chromatographic method for quantitative determination of residual solvents in pharmaceutical drug substances according to European Pharmacopoeia requirements. J Chromatogr A 1057:193-201

17. Battu PR, Reddy MS (2009) Residual solvents determination by HS-GC with flame ionization detector in Omeprazole pharmaceutical formulations. Int J PharmTech Res 1:230-234

18. Adepu S, Valli Kumari RV, Tulja Rani G (2015) A new validated GC-HS method for the determination of residual solvents in famotidine using FID. Int J Pharm Sci Rev Res 31:63-67

19. Puranik SB, Sharath S, Sanjay Pai PN (2012) Headspace gas chromatography analysis of residual solvents by using EC- 5 column. Int J Pharm Chem Res 1(1):22-27
20. Kantarjian $H$, Sawyers $C$, Hochhaus A, Guilhot F, Schiffer $C$, Gambacorti-Passerini C, Niederwieser D, Resta D, Capdeville R, Zoellner U, Talpaz M, Druker B (2002) Hematologic and cytogenetic responses to imatinib mesylate in chronic myelogenous leukemia. N Engl J Med 346:645-652

21. Druker BJ, Sawyers CL, Kantarjian H, Resta DJ, Reese SF, Ford JM, Capdeville R, Talpaz M (2001) Activity of a specific inhibitor of the BCR-ABL tyrosine kinase in the blast crisis of chronic myeloid leukemia and acute lymphoblastic leukemia with the Philadelphia chromosome. N Engl J Med 344:1038-1042

22. Ishikawa $Y$, Kiyoi $H$, Watanabe $K$, Miyamura K, Nakano $Y$, Kitamura K, Kohno A, Sugiura I, Yokozawa T, Hanamura A, Yamamoto K, lida H, Emi N, Suzuki R, Ohnishi K, Naoe T (2010) Trough plasma concentration of imatinib reflects BCR-ABL kinase inhibitory activity and clinical response in chronic-phase chronic myeloid leukemia: a report from the BINGO study. Cancer Sci 101:2186-2192

23. Dagher R, Cohen M, Williams G, Rothmann M, Gobburu J, Robbie G, Rahman A, Chen G, Staten A, Griebel D, Pazdur R (2002) Approval summary: imatinib mesylate in the treatment of metastatic and/or unresectable malignant gastrointestinal tumors. Clin Cancer Res 8:3034-3038

24. Cohen MH, Williams G, Johnson JR, Duan J, Gobburu J, Rahman A, Benson K, Leighton J, Kim SK, Wood R, Rothmann M, Chen G, Maung K, Staten AM, Pazdur R (2002) Approval summary for imatinib mesylate capsules in the treatment of chronic myelogenous leukemia. Clin Cancer Res 8:935-942

25. Dwivedi SP, Singh KK, Charan GD, Vasava C (2014) Process for preparation of amorphous imatinib mesylate. U.S. Patent No. US2014/0121215 A1

26. Teglia CM, Montemurro M, De Zan MM, Camara MS (2015) Multiple responses optimization in the development of a headspace gas chromatography method for the determination of residual solvents in pharmaceuticals. J Pharm Anal 5:296-306

27. Mistry NPK, Chetwyn L, Yazzie Dai DT, Quiroga KAC, Zhang HB, Dong Runes MW (2010) A generic headspace GC method for residual solvents in pharmaceutical: benefits, rationale and adaptations for new chemical entities. LCGC N Am 28:54-66

28. Somuramasami J, Wei Y, Soliman EF, Rustum AM (2011) Static headspace gas chromatographic method for the determination of low and high boiling residual solvents in betamethasone valerate. J Pharm Biomed Anal 54:242-247

29. Cheng C, Liu S, Mueller BJ, Yan Z (2010) A generic static headspace gas chromatography method for determination of residual solvents in drug substance. J Chromatogr A 1217:6413-6421

30. Agilent G1888A (2004) Headspace sampler operating manual, 1 st edn. Agilent Technologies, Inc., Santa Clara

31. Validation of Analytical Procedures Q2R1 (2005) Text and methodology, ICH harmonized tripartite guideline

Publisher's Note Springer Nature remains neutral with regard to jurisdictional claims in published maps and institutional affiliations. 